STRUCTURAL BIOLOGY COMMUNICATIONS

ISSN 2053-230X

Received 1 November 2021

Accepted 19 December 2021

Edited by F. T. Tsai, Baylor College of Medicine, Houston, USA

Keywords: Burkholderia pseudomallei; melioidosis; disulfiram; betaine aldehyde dehydrogenase; inhibition; drug repurposing.

PDB references: betaine aldehyde

dehydrogenase, 6 wsa; bound to cofactor, 6 wsb

Supporting information: this article has supporting information at journals.iucr.org/f

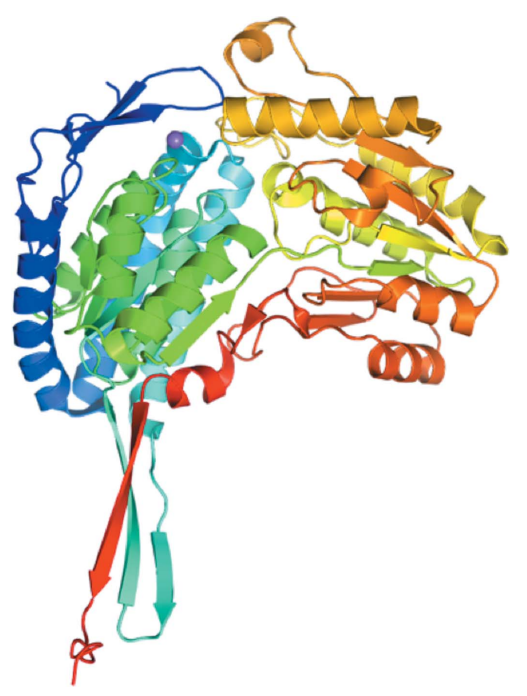

OPEN Ә ACCESS

\section{Crystal structure of betaine aldehyde dehydrogenase from Burkholderia pseudomallei}

\author{
Dylan K. Beard, ${ }^{a}$ Sandhya Subramanian, ${ }^{\text {b,c }}$ Jan Abendroth, ${ }^{\text {c,d }}$ David M. Dranow, \\ Thomas E. Edwards, ${ }^{c, d}$ Peter J. Myler ${ }^{\mathrm{b}, c, e}$ and Oluwatoyin A. Asojo ${ }^{\mathrm{a} *}$
}

\begin{abstract}
${ }^{a}$ Department of Chemistry and Biochemistry, Hampton University, 100 William R. Harvey Way, Hampton, VA 23668, USA, ${ }^{\mathbf{b}}$ Center for Global Infectious Disease Research, Seattle Children's Research Institute, 307 Westlake Avenue North Suite 500, Seattle, WA 98109, USA, ' Seattle Structural Genomics Center for Infectious Disease (SSGCID), Seattle, Washington, USA, ${ }^{\mathbf{d}}$ UCB-Bainbridge, Bainbridge Island, WA 98110, USA, and ${ }^{\mathbf{e}}$ Department of Global Health and Department of Biomedical Informatics and Medical Education, University of Washington, Seattle, WA 98195, USA. *Correspondence e-mail: oluwatoyin.asojo@hamptonu.edu
\end{abstract}

Burkholderia pseudomallei infection causes melioidosis, which is often fatal if untreated. There is a need to develop new and more effective treatments for melioidosis. This study reports apo and cofactor-bound crystal structures of the potential drug target betaine aldehyde dehydrogenase (BADH) from B. pseudomallei. A structural comparison identified similarities to BADH from Pseudomonas aeruginosa which is inhibited by the drug disulfiram. This preliminary analysis could facilitate drug-repurposing studies for B. pseudomallei.

\section{Introduction}

Burkholderia pseudomallei is a rod-shaped, motile, flagellated, soil-dwelling Gram-negative proteobacterium of the Burkholderiaceae family that thrives in tropical and subtropical regions (Gassiep et al., 2021). B. pseudomallei causes melioidosis, a deadly emerging opportunistic infection mainly of the immunocompromised (Hall et al., 2019; Poe et al., 1971; Veluthat et al., 2021). B. pseudomallei is transmitted through open wounds, contact with contaminated soil and water, ingestion or inhalation, and it is also a potential biological warfare agent (Goarant et al., 2021). Melioidosis is endemic in South Asia and Northern Australia, with $~ 165000$ cases annually; however, the global distribution of B. pseudomallei is unknown, as the associated disease is underreported and misdiagnosed (Patil et al., 2016; Poe et al., 1971; Veluthat et al., 2021). Typically, about 12 cases of melioidosis are reported annually in mainland USA, and most patients had traveled internationally; however, B. pseudomallei occurs naturally in Puerto Rico and the US Virgin Islands (Hall et al., 2019). Melioidosis symptoms include localized pain and swelling, ulcer, cough, headache, anorexia, joint pain, brain infection, seizures, fever, pneumonia, low blood pressure and abscesses (Hall et al., 2019; Poe et al., 1971; Veluthat et al., 2021). Thus, melioidosis may be misdiagnosed as tuberculosis, pneumonia or other diseases (Veluthat et al., 2021). Symptoms may appear a few days or several years after exposure, and the mortality rate of untreated melioidosis is around 90\% (Loveleena et al., 2004; Patil et al., 2016; Poe et al., 1971; Veluthat et al., 2021). Melioidosis is currently treated with two to eight weeks of intravenous antimicrobial therapy (ceftazidime or meropenem) followed by 3-6 months of oral antimicrobial therapy (amoxicillin/clavulanic acid or trimethoprim-sulfamethoxazole), 
but still results in $\sim 40 \%$ mortality (Fen et al., 2021). As a part of efforts to develop new therapeutics and diagnostics for melioidosis, the Seattle Structural Genomics Center for Infectious Disease (SSGCID) has determined the crystal structure of betaine aldehyde dehydrogenase (BADH) from B. pseudomallei (BpBADH). BADH catalyzes the irreversible oxidation of betaine aldehyde to the osmoprotectant betaine and is being investigated as a drug target for drug-resistant bacteria, notably Pseudomonas aeruginosa, because its inhibition blocks choline catabolism and leads to the accumulation of the highly toxic betaine aldehyde (González-Segura et al., 2009).

\section{Materials and methods}

\subsection{Production of $B p B A D H$}

Cloning, expression and purification were conducted as part of the Seattle Structural Genomics Center for Infectious Disease (SSGCID; Myler et al., 2009; Stacy et al., 2011) following standard protocols as described previously (Bryan et al., 2011; Choi et al., 2011; Serbzhinskiy et al., 2015). The full-length betaine aldehyde dehydrogenase gene from B. pseudomallei (BpBADH; UniProt Q3JLL8) encoding amino acids 1-489 was PCR-amplified from genomic DNA using the primers shown in Table 1.

The gene was cloned into the ligation-independent cloning (LIC; Aslanidis \& de Jong, 1990) expression vector pMCSG26 (Eschenfeldt et al., 2010) encoding a noncleavable C-terminal $6 \times$ His fusion tag (ORF-GHHHHHH). Plasmid DNA was transformed into chemically competent Escherichia coli BL21(DE3)R3 Rosetta cells. The plasmid containing Q3JLL8 was expression-tested, and 21 of culture was grown using autoinduction medium (Studier, 2005) in a LEX Bioreactor (Epiphyte Three Inc.) as described previously (Serbzhinskiy et al., 2015). The expression clone BupsA.00020.b.AE1.GE43326 is available at https://www.ssgcid.org/available-materials/ expression-clones/.

$B p$ BADH-His was purified using a two-step protocol consisting of an immobilized metal-affinity chromatography (IMAC) step and size-exclusion chromatography (SEC). All chromatography runs were performed on an ÄKTApurifier 10 (GE) using automated IMAC and SEC programs according to previously described procedures (Bryan et al., 2011). Thawed bacterial pellets were lysed by sonication in $200 \mathrm{ml}$ lysis buffer \{25 $\mathrm{m} M$ 4-(2-hydroxyethyl)-1-piperazineethanesulfonic acid (HEPES) pH 7.0, $500 \mathrm{mM} \mathrm{NaCl}, 5 \%$ glycerol, $0.5 \%$ 3-[(3-cholamidopropyl)dimethylammonio]-1-propanesulfonate (CHAPS), $30 \mathrm{~m} M$ imidazole, $10 \mathrm{~m} M \mathrm{MgCl}_{2}, 1 \mathrm{~m} M$ tris(2carboxyethyl)phosphine hydrochloride (TCEP), $250 \mu \mathrm{g} \mathrm{ml}^{-1}$ 4-(2-aminoethyl)benzenesulfonyl fluoride hydrochloride (AEBSF), $0.025 \%$ sodium azide . After sonication, the crude lysate was clarified with $20 \mu \mathrm{l}\left(25\right.$ units $\left.\mu \mathrm{l}^{-1}\right)$ Benzonase and incubated while mixing at room temperature for $45 \mathrm{~min}$. The

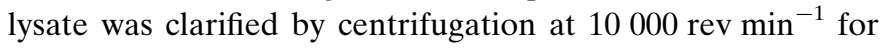
$1 \mathrm{~h}$ using a Sorvall centrifuge (Thermo Scientific). For the IMAC step, the clarified supernatant was passed over an
Table 1

Macromolecule-production information.

\begin{tabular}{|c|c|}
\hline \multirow{2}{*}{$\begin{array}{l}\text { Source organism } \\
\text { DNA source }\end{array}$} & Burkholderia pseudomallei $1710 \mathrm{~b}$ \\
\hline & $\begin{array}{l}\text { Dr Samuel I. Miller, University of } \\
\text { Washington, USA }\end{array}$ \\
\hline Forward primer & $5^{\prime}$-ATGTCCGTATACGGTCTGCAGC-3' \\
\hline Reverse primer & $5^{\prime}$-GAACACCGGTTGATAGCGGCC-3' \\
\hline Expression vector & pMCSG26 \\
\hline Expression host & E. coli BL21(DE3)R3 Rosetta cells \\
\hline Complete amino-acid sequence & MSVYGLQRLYIAGAHADATSGKTFDTFDPA \\
\hline & EWAAMTAMQRSRILRRAVELLRERNDAL \\
\hline & AELEMRDTGKPIAETRAVDIVTGADVIE \\
\hline & YYAGLATAIEGLQVPLRPESFVYTRREP \\
\hline & LGVCAGIGAWNYPIQIACWKSAPALAAG \\
\hline & NAMIFKPSEVTPLSALKLAEIYTEAGVP \\
\hline & AGVFNVVQGDGSVGALLSAHPGIAKVSF \\
\hline & TGGVETGKKVMSLAGASSLKEVTMELGG \\
\hline & KSPLIVFDDADLDRAADIAVTANFFSAG \\
\hline & QVCTNGTRVFVQQAVKDAFVERVLARVA \\
\hline & RIRVGKPSDSDTNFGPLASAAQLDKVLG \\
\hline & YIDSGKAEGAKLLAGGARLVNDHFASGQ \\
\hline & YVAPTVFGDCRDDMRIVREEIFGPVMSI \\
\hline & LSFETEDEAIARANATDYGLAAGVVTEN \\
\hline & LSRAHRA I HRLEAGICWINTWGESPAEM \\
\hline & PVGGYKQSGVGRENGITTLEHYTRIKSV \\
\hline & QVELGRYQPVFGHHHHHH \\
\hline
\end{tabular}

Ni-NTA HisTrap FF $5 \mathrm{ml}$ column (GE Healthcare) which had been pre-equilibrated with loading buffer $(25 \mathrm{~m} M$ HEPES $\mathrm{pH}$ 7.0, $500 \mathrm{mM} \mathrm{NaCl}, 5 \%$ glycerol, $30 \mathrm{~m} M$ imidazole, $1 \mathrm{~m} M$ TCEP, $0.025 \%$ sodium azide). The column was washed with 20 column volumes $(\mathrm{CV})$ of loading buffer and was eluted with loading buffer and $250 \mathrm{mM}$ imidazole in a linear gradient over $7 \mathrm{CV}$. Peak fractions, as determined by UV absorbance at $280 \mathrm{~nm}$, were pooled and concentrated using an Amicon concentrator to a volume of $5 \mathrm{ml}$ for SEC. For SEC, a SEC column (Superdex 75, GE) was equilibrated with running buffer [ $25 \mathrm{~m} M$ HEPES $\mathrm{pH} 7.0,500 \mathrm{mM} \mathrm{NaCl}, 5 \%$ glycerol, $2 \mathrm{~m} M$ dithiothreitol (DTT), $0.025 \%$ sodium azide]. The eluted peak fractions were collected and analyzed for the presence of $B p$ BADH by SDS-PAGE. The SEC peak fractions containing $B p$ BADH eluted as a single large peak at a molecular mass of $\sim 77 \mathrm{kDa}$. A dimer of $B p \mathrm{BADH}$ is expected to have a molecular mass of $\sim 106 \mathrm{kDa}$, while a monomer has a molecular mass of $\sim 53 \mathrm{kDa}$. BpBADH may be a monomer in the absence of a cofactor, while it dimerizes in the presence of the cofactor or other ligands. Further biophysical analysis is required to determine whether $B p B A D H$ dimerizes in the presence of NAD in solution. Interestingly, the dimer has been reported in more than 175 reported BADH structures with ligands, cofactors and inhibitors in the PDB and is consistent with the observed crystal form of $B p$ BADH with NAD (Fig. 1).

The peak fractions were pooled and concentrated to $34.72 \mathrm{mg} \mathrm{ml}^{-1}$ using an Amicon concentrator (Millipore). The protein concentration was assessed using the $\mathrm{OD}_{280}$ and a molar extinction coefficient of $46870 \mathrm{M}^{-1} \mathrm{~cm}^{-1}$. Purified protein was aliquoted into $200 \mu \mathrm{l}$ aliquots, flash-frozen in liquid nitrogen and stored at $-80^{\circ} \mathrm{C}$ until use for crystallization. The purified protein (batch BupsA.00020.b.AE1. PS38619) is available at https://www.ssgcid.org/availablematerials/ssgcid-proteins/. 
Table 2

Crystallization.

\begin{tabular}{|c|c|}
\hline Method & Sitting-drop vapor diffusion \\
\hline Plate type & 96-well Compact 300, Rigaku \\
\hline Temperature (K) & 287 \\
\hline $\begin{array}{l}\text { Protein concentration } \\
\left(\mathrm{mg} \mathrm{ml}^{-1}\right)\end{array}$ & 34.72 \\
\hline \multicolumn{2}{|c|}{ Buffer composition of protein solution } \\
\hline Apo crystals & $\begin{array}{l}25 \mathrm{~m} M \text { HEPES pH 7.0, } 500 \mathrm{~m} M \mathrm{NaCl} \\
5 \% \text { glycerol, } 2 \mathrm{~m} M \text { DTT, } 0.025 \% \text { azide }\end{array}$ \\
\hline NAD-bound crystals & $\begin{array}{l}25 \mathrm{~m} M \text { HEPES } \mathrm{pH} \text { 7.0, } 500 \mathrm{~m} M \mathrm{NaCl} \\
5 \% \text { glycerol, } 2 \mathrm{~m} M \text { DTT, } 0.025 \% \text { azide, } \\
4 \mathrm{~m} M \text { NAD }\end{array}$ \\
\hline \multicolumn{2}{|c|}{ Composition of reservoir solution } \\
\hline Apo structure & $\begin{array}{l}\text { JCSG+ condition F7: } 0.8 M \text { succinate } \mathrm{pH} \\
\quad 7.0\end{array}$ \\
\hline NAD-bound structure & $\begin{array}{l}\text { Morpheus condition H11: } 10 \% \text { PEG } 4000 \text {, } \\
20 \% \text { glycerol, } 0.02 M \text { sodium L-glutamate, } \\
0.02 M \text { DL-alanine, } 0.02 M \text { glycine, } 0.02 M \\
\text { DL-lysine, } 0.02 M \text { DL-serine, } 0.1 M \text { bicine/ } \\
\text { Trizma pH } 8.5\end{array}$ \\
\hline Volume and ratio of drop & $0.4 \mu \mathrm{l}$ protein plus $0.4 \mu \mathrm{l}$ reservoir \\
\hline Volume of reservoir $(\mu \mathrm{l})$ & 80 \\
\hline Cryoprotectant & $20 \%$ ethylene glycol \\
\hline
\end{tabular}

\subsection{Crystallization}

Purified $B p B A D H-H i s$ was screened for crystallization in 96-well sitting-drop plates against the JCSG++ HTS (Jena Bioscience), MCSG1 (Molecular Dimensions) and Morpheus (Rigaku Reagents; Gorrec, 2009, 2015) crystal screens. The protein solution for the apo structure did not contain NAD, whereas $4 \mathrm{~m} M$ NAD was added to the protein solution for the NAD-bound complex (Table 2). Equal volumes of protein solution $(0.4 \mu \mathrm{l})$ and precipitant solution were set up at $287 \mathrm{~K}$
Table 3

Data collection and processing.

Values in parentheses are for the outer shell.

\begin{tabular}{|c|c|c|}
\hline PDB code & 6wsa & 6wsb \\
\hline Ligand & - & NAD \\
\hline Diffraction source & 21-ID-F, APS & 21-ID-F, APS \\
\hline Wavelength $(\AA)$ & 0.97872 & 0.97872 \\
\hline Temperature (K) & 100 & 100 \\
\hline Detector & $\begin{array}{l}\text { RayoniX MX300HE } \\
\text { CCD }\end{array}$ & $\begin{array}{l}\text { RayoniX MX300HE } \\
\text { CCD }\end{array}$ \\
\hline $\begin{array}{l}\text { Crystal-to-detector distance } \\
\qquad(\mathrm{mm})\end{array}$ & 270 & 200 \\
\hline Rotation range per image $\left(^{\circ}\right)$ & 1 & 1 \\
\hline Total rotation range $\left(^{\circ}\right)$ & 60 & 150 \\
\hline Space group & $P 6_{2} 22$ & $P 2_{1} 2_{1} 2$ \\
\hline$a, b, c(\AA)$ & $107.86,107.86,233.53$ & $99.27,156.70,76.23$ \\
\hline$\alpha, \beta, \gamma\left({ }^{\circ}\right)$ & $90,90,120$ & $90,90,90$ \\
\hline Mosaicity $\left({ }^{\circ}\right)$ & 0.143 & 0.103 \\
\hline Resolution range $(\AA)$ & $49.51-2.05(2.10-2.05)$ & $43.09-1.55(1.59-1.55)$ \\
\hline Total No. of reflections & $362438(26952)$ & $1054995(75766)$ \\
\hline No. of unique reflections & $51154(3702)$ & $172302(12622)$ \\
\hline Completeness (\%) & $99.9(99.9)$ & $99.9(100.0)$ \\
\hline Multiplicity & $7.09(7.28)$ & $6.12(6.00)$ \\
\hline$\langle I / \sigma(I)\rangle$ & $12.86(3.50)$ & $16.47(3.02)$ \\
\hline$R_{\text {r.i.m. }}$ & $0.101(0.548)$ & $0.083(0.621)$ \\
\hline $\begin{array}{l}\text { Overall } B \text { factor from } \\
\text { Wilson plot }\left(\AA^{2}\right)\end{array}$ & 32.748 & 20.398 \\
\hline
\end{tabular}

against reservoir $(80 \mu \mathrm{l})$ in sitting-drop vapor-diffusion format. The final crystallization precipitant was JCSG+ condition F7 for the apo form and Morpheus condition H11 for the NADbound form (see Table 2). After cryoprotectant exchange into crystallization solution supplemented with $20 \%$ ethylene

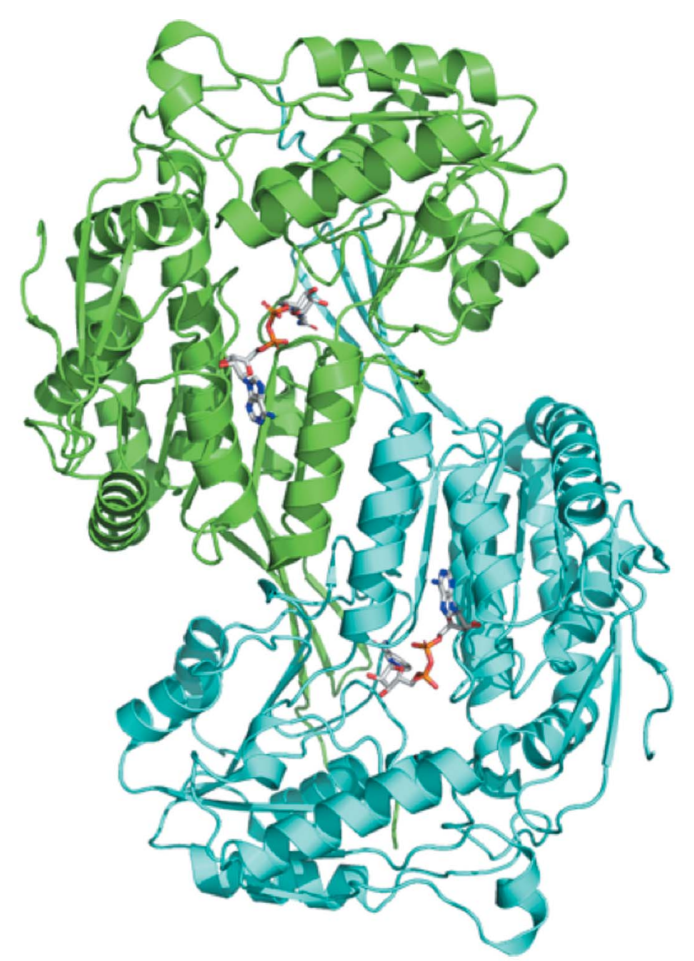

(b)

Figure 1

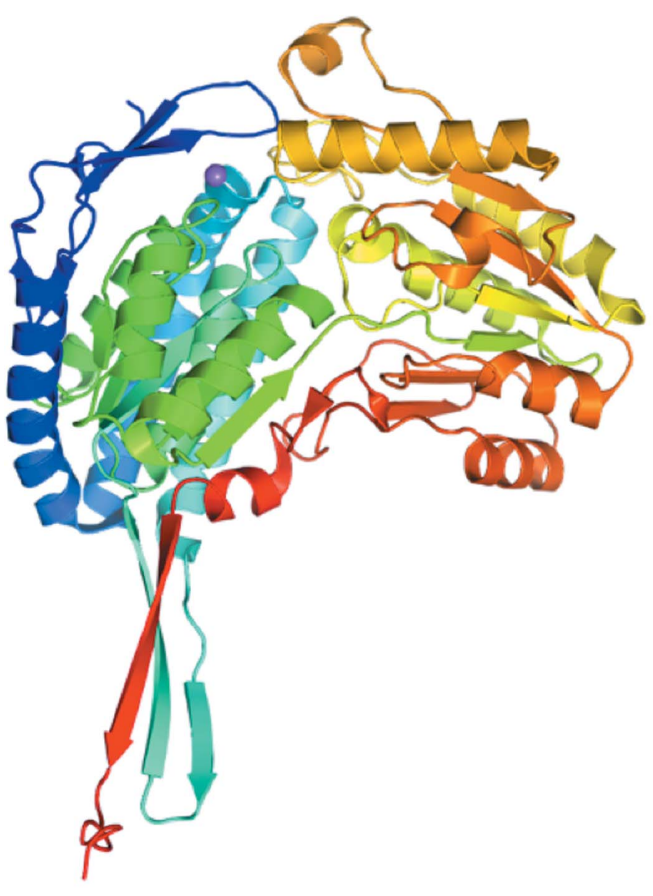

(a)

Structure of B. pseudomallei betaine aldehyde dehydrogenase (BpBADH). (a) Monomer of apo BpBADH (rainbow colored from blue at the Nterminus to red at the C-terminus. (b) Dimer of $B p B A D H$ with NAD (monomers are shown as aquamarine and cyan ribbons, with NAD shown as sticks). 


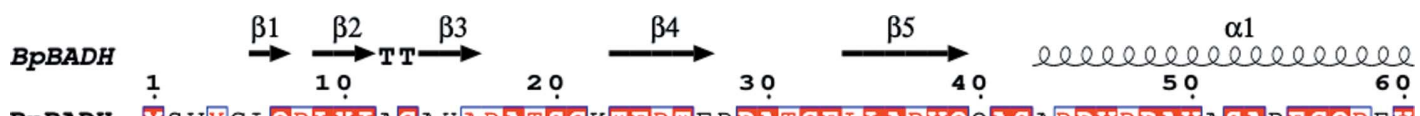

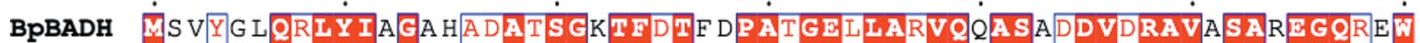
PaBADH MAREEEQKLYIGGRYVEASSGATEETI NPANG FVIAKVQRASREDVERAVQSAVEGQKVW

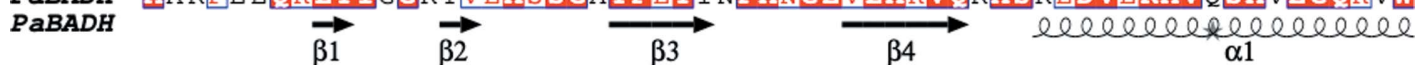
$\alpha 2 \quad \alpha 3 \quad \alpha 4 \quad \alpha 5$

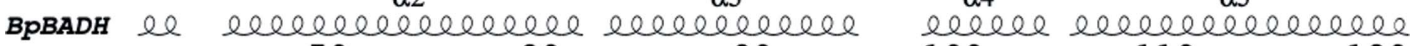
$\begin{array}{llllll}70 & 80 & 90 & 100 & 110 & 120\end{array}$ BPBADH AAMTAMQRSRILRRAVELLRFRNDALAELFMRDTGKRIABTRAVD IVTGADVIFYYAGLA PABADH AAMTAMORSRILRRAVDILRFRNDELAALFTLDTGKPLAFTRSVDIVTGADVLEYYAGLV

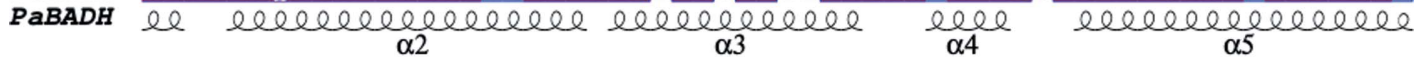

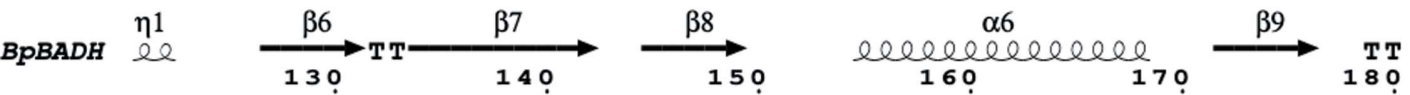
BPBADH TAIFGLQVP LRP E SVYTRRBP L GVCAGI GANNYPIQIACWKSAPALAAGNAMIFKP SWV PABADH PAIFGEQIPLRETSFVYTRRFPIGVVAGI GANNYPVQ I ALEKSAPALAAGNAMIFKPS BV

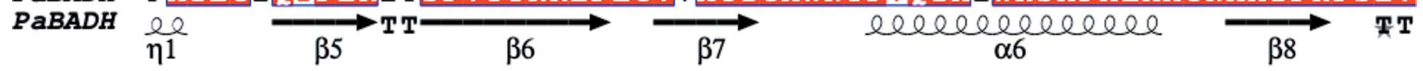

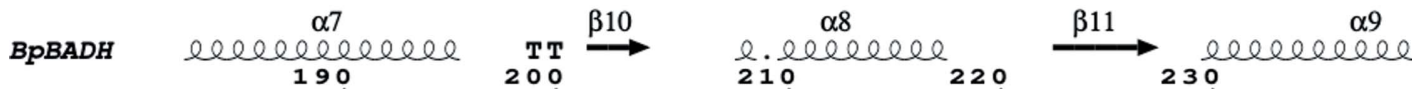
BPBADH TPISALKLAEIYTFAGVPAGVENVVQGDG. SVGALISARGIARVSFTGGVETGKKVMS I PABADH IPLTALKLABIYTBAGVPDGVENVLTGSGREVGQWLTEHPLIEKISTTGGT STGKKVVAS

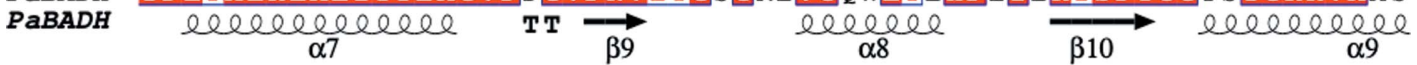

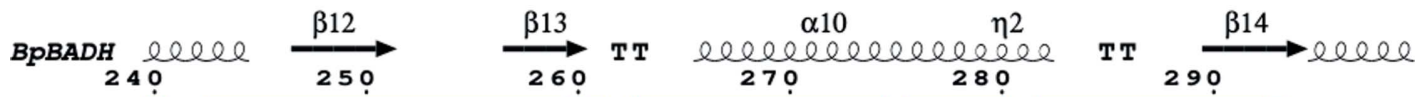
BPBADH AGASSLKEVTMFLGGKSIIVIDDADLDRAADIAVTANEFSAGQVCTNGTRVEVQQAVKD PaBADH ASSSSIKEVTMEIGGKSPIIIEPDADLDRAADIAVMANESSSGOVCTNGTRVIIHRSQQA

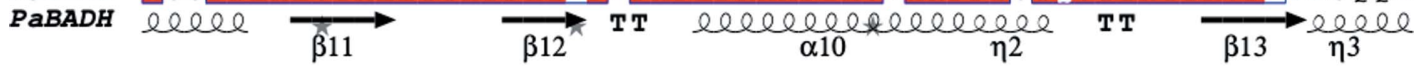

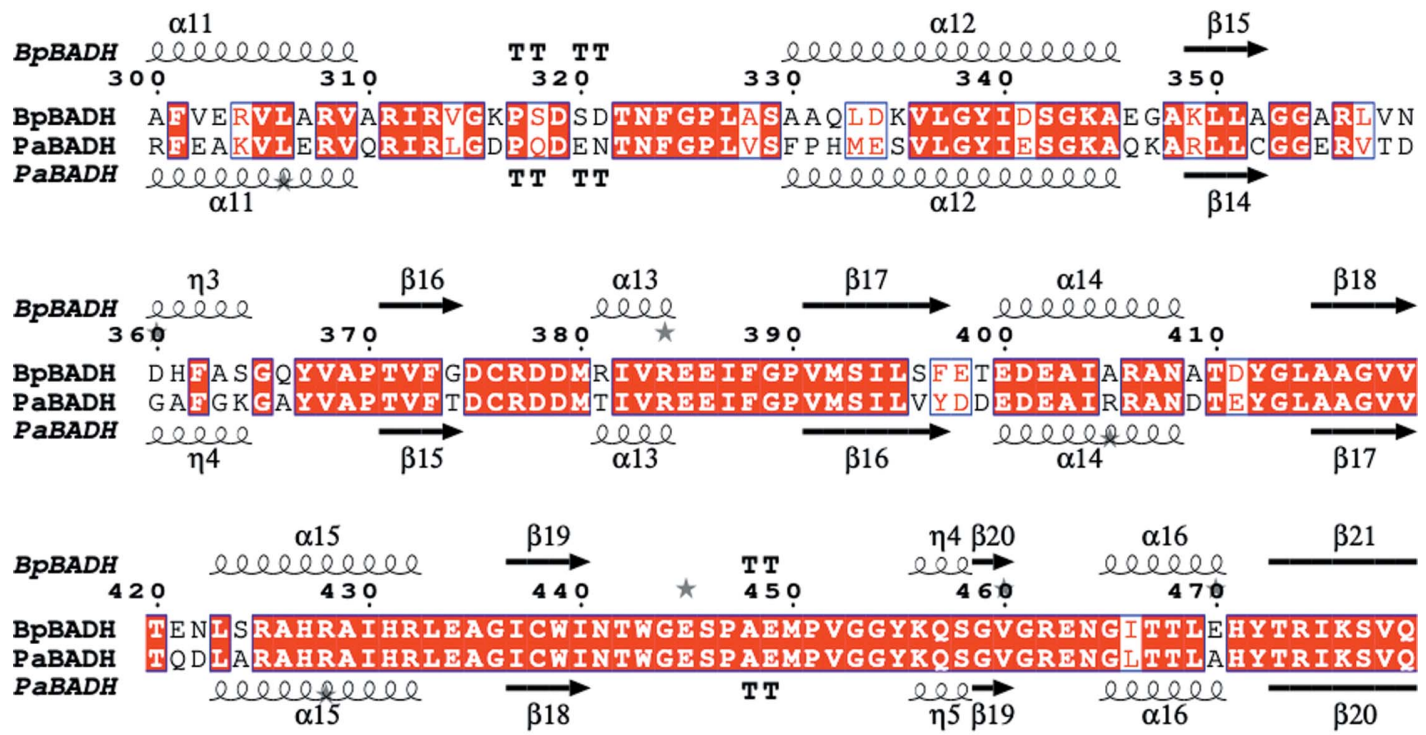
BPBADH
480
BPBADH VBLERYQRVEG
PaBADH VELGDYA SVE.
PaBADH $\rightarrow$

Figure 2

Structural and primary-sequence alignment of $B p B A D H$ and PaBADH. The secondary-structure elements shown are $\alpha$-helices $(\alpha), 3_{10}$-helices $(\eta)$, $\beta$-strands $(\beta)$ and $\beta$-turns (TT). Identical residues are shown in white on a red background and conserved residues are shown in red. 
Table 4

Structure solution and refinement.

Values in parentheses are for the outer shell.

\begin{tabular}{lll}
\hline PDB code & 6 wsa & $6 \mathrm{wsb}$ \\
\hline Ligand & Glycerol & NAD \\
Resolution range $(\AA)$ & $49.51-2.05(2.08-2.05)$ & $43.09-1.55(1.57-1.55)$ \\
Completeness $(\%)$ & 96.1 & 96.4 \\
$\sigma$ Cutoff & $F>0.000 \sigma(F)$ & $F>0.000 \sigma(F)$ \\
No. of reflections, working set & $49171(1957)$ & $166209(4765)$ \\
No. of reflections, test set & $2932(109)$ & $10050(297)$ \\
Final $R_{\text {cryst }}$ & $0.140(0.2203)$ & $0.144(0.2064)$ \\
Final $R_{\text {free }}$ & $0.173(0.2521)$ & $0.169(0.2342)$ \\
Cruickshank DPI & 0.183 & 0.070 \\
No. of non-H atoms & & \\
$\quad$ Protein & 3666 & 7322 \\
$\quad$ Ion & 1 & - \\
Ligand & 60 & 100 \\
Solvent & 501 & 1388 \\
$\quad$ Total & 4228 & 8810 \\
R.m.s. deviations & & \\
$\quad$ Bond lengths $(\AA)$ & 0.006 & 0.006 \\
$\quad$ Angles $\left({ }^{\circ}\right)$ & 0.775 & 0.85 \\
Average $B$ factors $\left(\AA^{2}\right)$ & 33.0 & 15.3 \\
$\quad$ Protein & 32.1 & - \\
Ion & 58.9 & 31.7 \\
Ligand & 42.6 & 30.8 \\
$\quad$ Water & & 97.1 \\
Ramachandran plot & 97.1 & 2.9 \\
$\quad$ Most favored $(\%)$ & 2.9 & \\
Allowed $(\%)$ & & \\
\hline
\end{tabular}

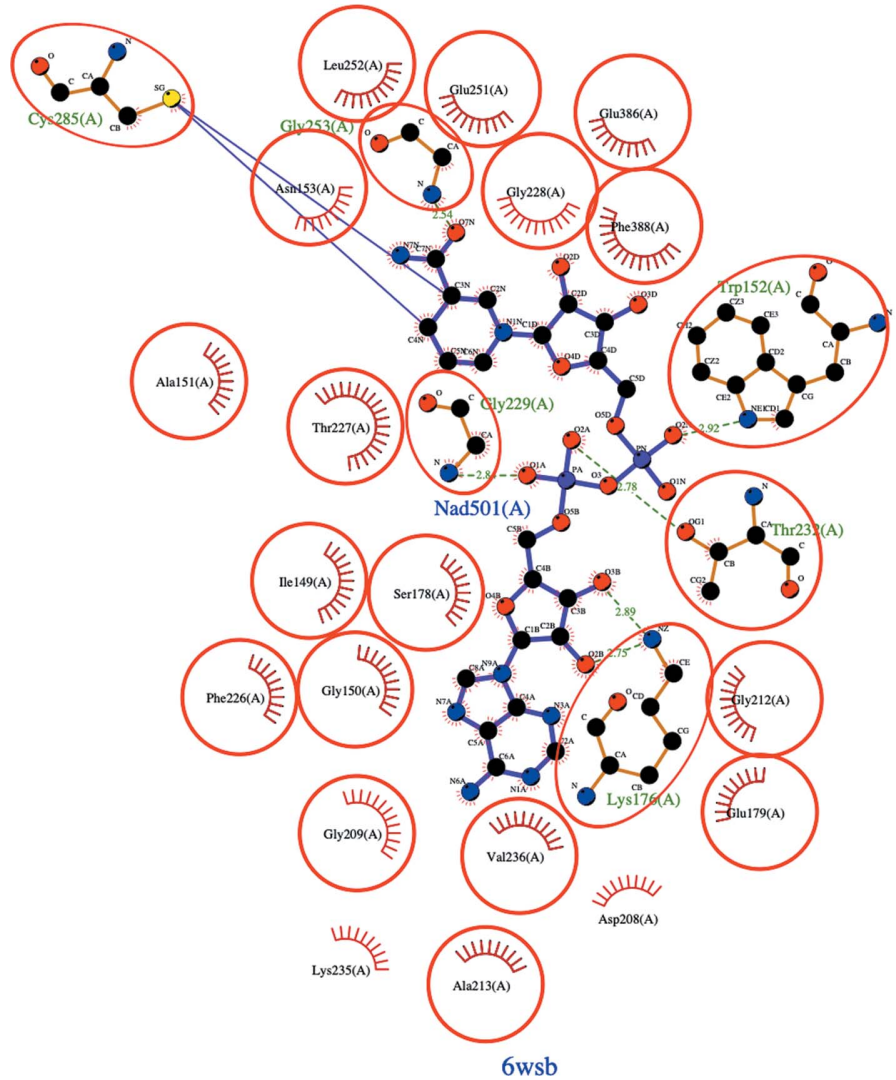

glycol, the crystals were harvested and flash-cooled by plunging them into liquid nitrogen.

\subsection{Data collection and processing}

Data were collected at $100 \mathrm{~K}$ on beamline 21-ID-F at the Advanced Photon Source (APS), Argonne National Laboratory (see Table 3). Data sets were reduced with XSCALE (Kabsch, 2010). Raw X-ray diffraction images are available from the Integrated Resource for Reproducibility in Macromolecular Crystallography at https://www.proteindiffraction.org/.

\subsection{Structure solution and refinement}

The structures were solved by molecular replacement with Phaser (McCoy et al., 2007) from the CCP4 suite of programs (Collaborative Computational Project, Number 4, 1994; Krissinel et al., 2004; Winn et al., 2011) using PDB entry 2wox (Díaz-Sánchez et al., 2011) as the search model. The structure was refined using iterative cycles of Phenix (Liebschner et al., 2019) followed by manual rebuilding of the structure using Coot (Emsley \& Cowtan, 2004; Emsley et al., 2010). The quality of both structures was checked using MolProbity (Chen et al., 2010). All data-reduction and refinement statistics are shown in Table 4. The structures of apo $B p B A D H$ and $B p B A D H$ with NAD were refined to resolutions of 2.05 and

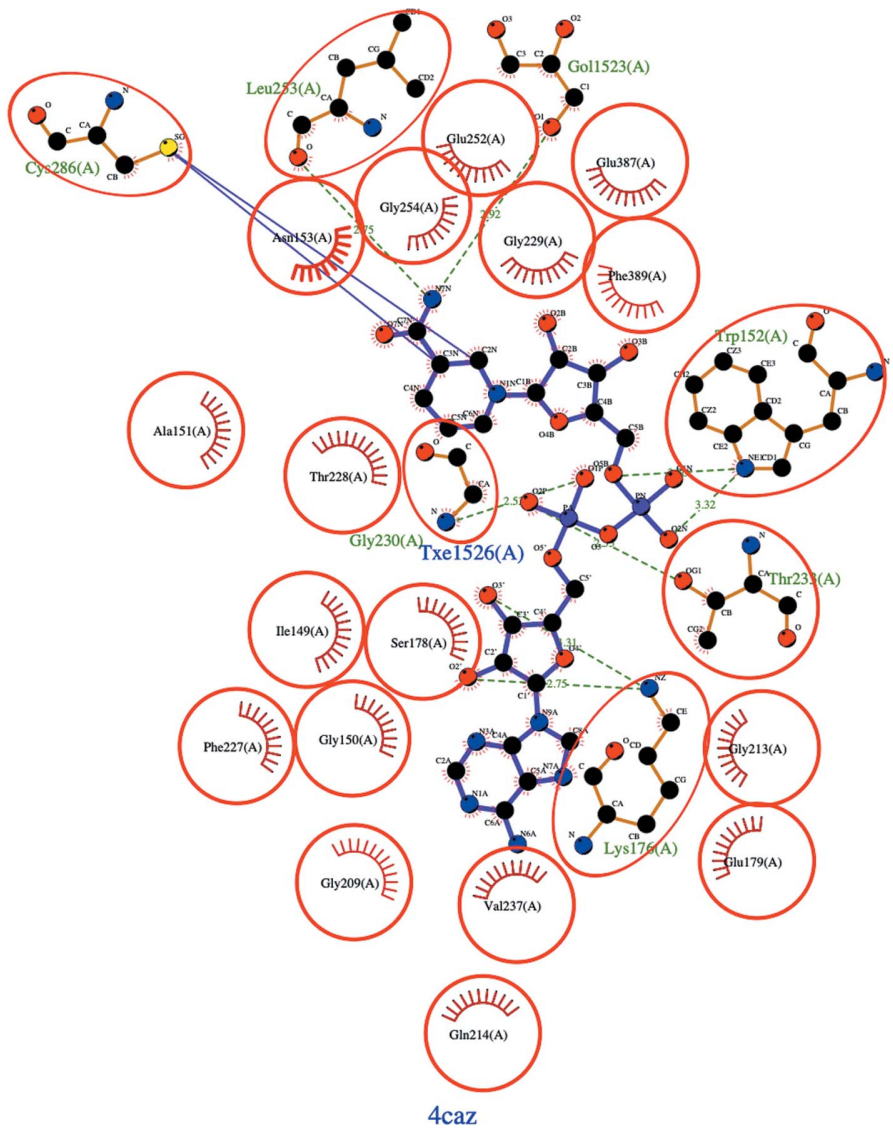

Figure 3

LIGPLOT analysis reveals that the cofactor-binding domains of BpBADH (PDB entry 6wsb) and PaBADH (PDB entry 4caz) are well conserved (circles indicate identical residues). Both structures show the conserved catalytic cysteine irreversibly inhibited by disulfiram. 
$1.55 \AA$ A respectively. Structural figures were analyzed and prepared using PyMOL (DeLano, 2002). Multiple sequence alignments were generated with Clustal Omega ( $\mathrm{Li}$ et al., 2015). Coordinates and structure factors have been deposited in the Protein Data Bank (https://www.rcsb.org/; Berman et al., 2000) with accession numbers 6wsa and 6wsb for apo $B p \mathrm{BADH}$ and $\mathrm{BPBADH}$ in complex with NAD, respectively.

\section{Results and discussion}

The two structures reported here are of apo $B p B A D H$ and its complex with the cofactor NAD (Fig. 1). The monomers are very similar and have an r.m.s.d. of $\sim 0.17 \AA$ for main-chain atoms. The 489 amino acids in each monomer fold as $20.4 \%$ $\beta$-strand, $39.3 \% \alpha$-helix, $2.5 \% 33_{10}$-helix and $37.8 \%$ loops, forming six $\beta-\alpha-\beta$ motifs that contain five $\beta$-sheets (four mixed and one antiparallel). The structure also contains 21 helices, 21 strands, four $\beta$-hairpins, four $\beta$-bulges and 25 helix-helix interactions. $B p \mathrm{BADH}$ has a prototypical BADH topology and shares considerable structure and sequence similarity with the ortholog from P. aeruginosa (PaBADH; Fig. 2). The 489amino-acid sequence of $P a \mathrm{BADH}$ folds as $19.6 \% \beta$-strand, $38.2 \% \alpha$-helix, $2.5 \% 3_{10}$-helix and $39.7 \%$ loops (Fig. 2 ).

The structural similarities and motifs associated with the BADHs from both organisms may accelerate drug-discovery efforts. PaBADH is known to be inhibited by disulfiram through the catalytic cysteine (Velasco-García et al., 2006); thus, we hypothesize that $B p$ BADH will likewise be inhibited by disulfiram. Disulfiram binds irreversibly to Cys 286 in $P a$ BADH, which is in the highly conserved cofactor-binding cavity of $P a \mathrm{BADH}$ and $\mathrm{BpBADH}$; the corresponding residue is Cys285 in BpBADH (Figs. 2 and 3). Disulfiram is an irreversible inhibitor that leads to a buildup of betaine aldehyde, which becomes toxic in bacterial cells. The toxicity in the bacterial cells stops bacterial growth (Velasco-García et al., 2006). Since disulfiram is FDA-approved for treating chronic alcoholism, preliminary studies suggest that it could be repurposed as a lead compound for melioidosis. Furthermore, due to the structural similarity between $P a \mathrm{BADH}$ and $B p \mathrm{BADH}$, the lessons learned in drug discovery for the former could accelerate efforts in addressing melioidosis.

\section{Conclusion}

The high-resolution structures of betaine aldehyde dehydrogenase from B. pseudomallei (BpBADH) and P. aeruginosa $(P a B A D H)$ reveal a conserved NAD-dependent topology and structural similarity. Since the key amino-acid residues in inhibitor-binding sites are conserved, the previous studies on $P a$ BADH could facilitate the development of small-molecule inhibitors of $B p B A D H$.

\section{Acknowledgements}

The SSGCID consortium is directed by Dr Peter Myler (principal investigator) and comprises many different scientists working at multiple centers towards determining the three-dimensional structures of proteins from biodefense organisms and emerging infectious diseases. In particular, we would like to thank the SSGCID cloning, protein-production and X-ray crystallography groups at the Center for Global Infectious Disease Research, the University of Washington and UCB.

\section{Funding information}

This work was supported by federal funds from the National Institute of Allergy and Infectious Diseases (NIAID), National Institutes of Health (NIH), Department of Health and Human Services under Contract No. HHSN272201700059C from 1 September 2017. (SSGCID was funded under NIAID Contracts Nos. HHSN272201200025C from 1 September 2012 through 31 August 2017 and HHSN272200700057C from 28 September 2007 through 27 September 2012.) Dylan K. Beard was part of a Hampton University Chemistry Education and Mentorship Coursebased Undergraduate Research pilot (HU-ChEM CURES) funded by the NIGMS (award No. 1U01GM138433-01 to OAA).

\section{References}

Aslanidis, C. \& de Jong, P. J. (1990). Nucleic Acids Res. 18, 6069-6074. Berman, H. M., Westbrook, J., Feng, Z., Gilliland, G., Bhat, T. N., Weissig, H., Shindyalov, I. N. \& Bourne, P. E. (2000). Nucleic Acids Res. 28, 235-242.

Bryan, C. M., Bhandari, J., Napuli, A. J., Leibly, D. J., Choi, R., Kelley, A., Van Voorhis, W. C., Edwards, T. E. \& Stewart, L. J. (2011). Acta Cryst. F67, 1010-1014.

Chen, V. B., Arendall, W. B., Headd, J. J., Keedy, D. A., Immormino, R. M., Kapral, G. J., Murray, L. W., Richardson, J. S. \& Richardson, D. C. (2010). Acta Cryst. D66, 12-21.

Choi, R., Kelley, A., Leibly, D., Nakazawa Hewitt, S., Napuli, A. \& Van Voorhis, W. (2011). Acta Cryst. F67, 998-1005.

Collaborative Computational Project, Number 4 (1994). Acta Cryst. D50, 760-763.

DeLano, W. L. (2002). PyMOL. http://www.pymol.org.

Díaz-Sánchez, Á. G., González-Segura, L., Rudiño-Piñera, E., Lira-Rocha, A., Torres-Larios, A. \& Muñoz-Clares, R. A. (2011). Biochem. J. 439, 443-452.

Emsley, P. \& Cowtan, K. (2004). Acta Cryst. D60, 2126-2132.

Emsley, P., Lohkamp, B., Scott, W. G. \& Cowtan, K. (2010). Acta Cryst. D66, 486-501.

Eschenfeldt, W. H., Maltseva, N., Stols, L., Donnelly, M. I., Gu, M., Nocek, B., Tan, K., Kim, Y. \& Joachimiak, A. (2010). J. Struct. Funct. Genomics, 11, 31-39.

Fen, S. H. Y., Tandhavanant, S., Phunpang, R., Ekchariyawat, P., Saiprom, N., Chewapreecha, C., Seng, R., Thiansukhon, E., Morakot, C., Sangsa, N., Chayangsu, S., Chuananont, S., Tanwisaid, K., Silakun, W., Buasi, N., Chaisuksant, S., Hompleum, T., Chetchotisakd, P., Day, N. P. J., Chantratita, W., Lertmemongkolchai, G., West, T. E. \& Chantratita, N. (2021). Antimicrob. Agents Chemother. 65, e02230-20.

Gassiep, I., Burnard, D., Bauer, M. J., Norton, R. E. \& Harris, P. N. (2021). Future Microbiol. 16, 271-288.

Goarant, C., Dellagi, K. \& Picardeau, M. (2021). Yale J. Biol. Med. 94, 351-360.

González-Segura, L., Rudiño-Piñera, E., Muñoz-Clares, R. A. \& Horjales, E. (2009). J. Mol. Biol. 385, 542-557.

Gorrec, F. (2009). J. Appl. Cryst. 42, 1035-1042.

Gorrec, F. (2015). Acta Cryst. F71, 831-837. 
Hall, C. M., Jaramillo, S., Jimenez, R., Stone, N. E., Centner, H., Busch, J. D., Bratsch, N., Roe, C. C., Gee, J. E., Hoffmaster, A. R., Rivera-Garcia, S., Soltero, F., Ryff, K., Perez-Padilla, J., Keim, P., Sahl, J. W. \& Wagner, D. M. (2019). PLoS Negl. Trop. Dis. 13, e0007727.

Kabsch, W. (2010). Acta Cryst. D66, 125-132.

Krissinel, E. B., Winn, M. D., Ballard, C. C., Ashton, A. W., Patel, P., Potterton, E. A., McNicholas, S. J., Cowtan, K. D. \& Emsley, P. (2004). Acta Cryst. D60, 2250-2255.

Li, W., Cowley, A., Uludag, M., Gur, T., McWilliam, H., Squizzato, S., Park, Y. M., Buso, N. \& Lopez, R. (2015). Nucleic Acids Res. 43, W580-W584.

Liebschner, D., Afonine, P. V., Baker, M. L., Bunkóczi, G., Chen, V. B., Croll, T. I., Hintze, B., Hung, L.-W., Jain, S., McCoy, A. J., Moriarty, N. W., Oeffner, R. D., Poon, B. K., Prisant, M. G., Read, R. J., Richardson, J. S., Richardson, D. C., Sammito, M. D., Sobolev, O. V., Stockwell, D. H., Terwilliger, T. C., Urzhumtsev, A. G., Videau, L. L., Williams, C. J. \& Adams, P. D. (2019). Acta Cryst. D75, 861-877.

Loveleena, Chaudhry, R. \& Dhawan, B. (2004). J. Assoc. Physicians India, 52, 417-420.

McCoy, A. J., Grosse-Kunstleve, R. W., Adams, P. D., Winn, M. D., Storoni, L. C. \& Read, R. J. (2007). J. Appl. Cryst. 40, 658-674.
Myler, P. J., Stacy, R., Stewart, L., Staker, B. L., Van Voorhis, W. C., Varani, G. \& Buchko, G. W. (2009). Infect. Disord. Drug Targets, 9, 493-506.

Patil, H. G., Gundavda, M., Shetty, V., Soman, R., Rodriques, C. \& Agashe, V. M. (2016). J. Orthop. 13, 40-42.

Poe, R. H., Vassallo, C. L. \& Domm, B. M. (1971). Am. Rev. Respir. Dis. 104, 427-431.

Serbzhinskiy, D. A., Clifton, M. C., Sankaran, B., Staker, B. L., Edwards, T. E. \& Myler, P. J. (2015). Acta Cryst. F71, 594-599.

Stacy, R., Begley, D. W., Phan, I., Staker, B. L., Van Voorhis, W. C., Varani, G., Buchko, G. W., Stewart, L. J. \& Myler, P. J. (2011). Acta Cryst. F67, 979-984.

Studier, F. W. (2005). Protein Expr. Purif. 41, 207-234.

Velasco-García, R., Zaldívar-Machorro, V. J., Mújica-Jiménez, C., González-Segura, L. \& Muñoz-Clares, R. A. (2006). Biochem. Biophys. Res. Commun. 341, 408-415.

Veluthat, C., Venkatnarayan, K., Padaki, P. \& Krishnaswamy, U. M. (2021). BMJ Case Rep. 14, e242499.

Winn, M. D., Ballard, C. C., Cowtan, K. D., Dodson, E. J., Emsley, P., Evans, P. R., Keegan, R. M., Krissinel, E. B., Leslie, A. G. W., McCoy, A., McNicholas, S. J., Murshudov, G. N., Pannu, N. S., Potterton, E. A., Powell, H. R., Read, R. J., Vagin, A. \& Wilson, K. S. (2011). Acta Cryst. D67, 235-242. 